\title{
Heuristic Control of Multi-Stage Desalination Plants Under Variable Available Power*
}

\author{
Alvaro Serna, Fernando Tadeo, David Torrijos
}

\begin{abstract}
A heuristic strategy is presented and evaluated to operate desalination plants designed for variable power availability. This control strategy is based on two consecutive steps: first developing a prioritized list of units of the water plant based on the current state of the plant and the expected water demand, and then distributing the available energy among those units following the prioritized list. The proposed strategy is evaluated on a case study: a desalination plant designed for production of demineralized water powered by a combination of wind and wave energy. Simulation results show the correct operation of the plant under this control.
\end{abstract}

\section{INTRODUCTION}

Desalination is becoming increasingly used in many areas of the world to satisfy the demand of water. This process produces water (for human or industrial use), by removing most of the salts, generally from sea or brackish waters. Desalination systems are ubiquous: The capacity estimation for 2015 goes beyond $120 \mathrm{Mm}^{3} /$ day. The cost of drinkable water obtained from desalination is decreasing. Although currently most large-scale desalination plants are connected to the grid, renewable energies are being introducing specially in small desalination plants, located in areas without a reliable electricity grid. Australia is an important exception, where the biggest seawater desalination plants are powered by renewable energies: see Garcia-Rodriguez (2002) and Mathioulakis et al. (2007) for a detailed description of desalination plants powered by renewable energy sources.

This paper concentrates in Reverse Osmosis (RO) plants, as it is the most frequently used process for small and medium sized plants: RO uses high pressures to force water molecules through a semi permeable membrane, retaining salt particles on the high pressure side (See, for example, Fritzmann et al., 2007, and Penate and Garcia-Rodriguez, 2012, for some general references of $\mathrm{RO}$ desalination). The pressure required goes from 40 bars to 80 bars depending on salt concentrations: see for example Wong et al. (2012). This pressure is supplied by high-pressure pumps (positivedisplacement, centrifugal, etc), that consume a significant amount of electric power. When renewable energy sources are the main source of energy, a central problem is balancing the power consumption with the power production; this is

This work was funded by Ministerio de Ciencia e Innovación (Spain) under grant DPI2014-54530-R. H2Ocean receives funding from the European Union Seventh Framework Programme (FP7/2007-2013) under grant agreement $\mathrm{n}^{\circ} 288145$.

A. Serna and F. Tadeo are with the University of Valladolid, 47005 Valladolid, Spain (e-mail: fernando@autom.uva.es).

D. Torrijos is with SETA S.L., Rivas-Vaciamadrid, Madrid, Spain solved here using the active load concept used in microgrids (See Peas Lopes et al., 2006, Vandoorn et al., 2011 and references therein).

More precisely, small desalination plants are considered here, as they are frequently installed in remote areas powered by renewable energies (See Seibert, 2004 and Tadeo et al. (2011), and a proposal for its control is presented and evaluated here, that has been developed in the context of the H2Ocean project*. In fact, many different ideas have been proposed in the literature for control of these systems, as control significantly improves the performance (see, for example, Robertson et al., 1996, Gambier and Badreddin, 2003 and Palacin et al., 2011 for some previous control proposals). In this case, following the proposal studied by some of the authors in (Serna and Tadeo, 2013), the desalination plant is considered to be partitioned in several stages, consisting of parallel lines connected through buffer tanks; each of them operate at a constant working point, and can be connected or disconnected depending on the available energy and the amount of water stored in each tank. Thus, the control proposal discussed here is based on deciding which sections would be switched on or shutdown. Unused energy would be temporarily stored in batteries for later use. In order to minimize the use of batteries most of the power should be immediately consumed by the desalination system, but at the same time the availability of water in all the sections of the process should be ensured, and no production is lost.

\section{Problem Statement}




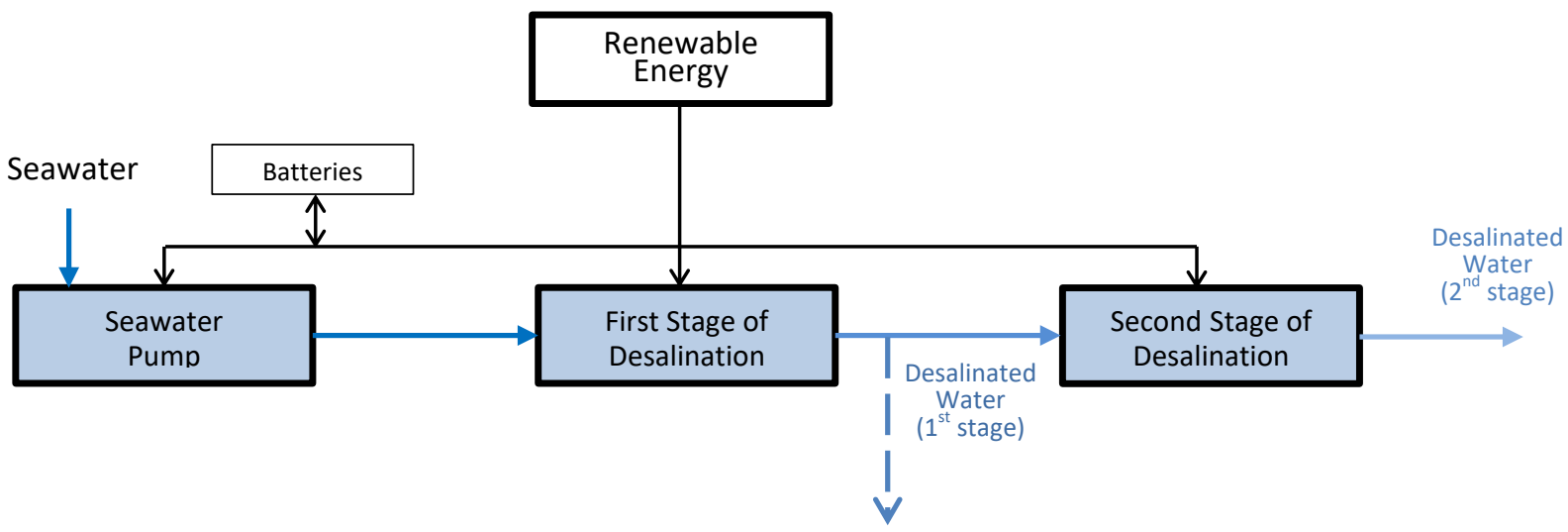

Figure 1: Renewable-Energy Powered Desalination system under study

Figure 1 presents the main components of the desalination plants studied here. If power supply changes with time, the production of water is going to change with time to adapt to the available power. Changing the working point of the plant by selecting a different flow/pressure setpoint is not adequate for most Reverse Osmosis systems, as they are designed to correctly operate at a given setpoint. Thus, in a previous paper (Serna and Tadeo, 2013) it was proposed to partition the high pressure part of the RO plant in different parallel sections, with each section operating as a standard RO plant (producing water at a fixed working point), to be connected

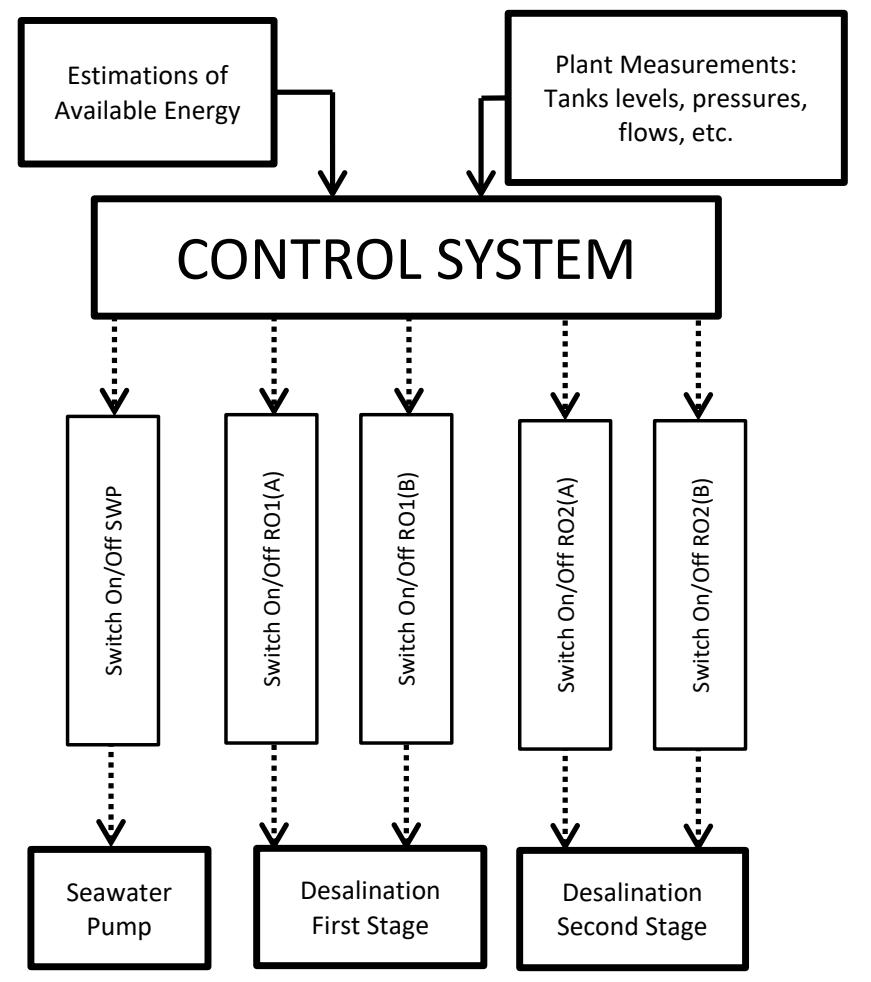

Figure 2: Proposed structure of the control system

or disconnected as needed following a pre-programmed sequential functional chart. This proposal was selected as it is simple to implement in existing control systems of Desalination plants, making possible to operate the whole plant as an active load by disconnecting temporarily components until the predicted electrical consumption is fully used. Unfortunately the approach previously presented is not adequate when there are a significant number of units of consumption that are being used and conflicting control objectives; in particular it is not adequate for multi-stage desalination plants operated by lines, as the number of components with high electrical consumptions (high pressure pumps) is too big to make a functional block diagram that represents accurately the control objectives. Thus, an alternative procedure is presented in next section, which combines the possibility of implementation in existing control hardware (PLCs) with the fulfillment of conflicting control objectives.

\section{CONTROL SYSTEM}

This section studies the control system to be developed for that class of desalination plants.

\section{A. Control Structure}

A central component to ensure smooth operation of the facility is the control system, to balance power consumption with the available power, by deciding which components of the plant are connected or disconnected. These components are:

1. The seawater pump (SWP).

2. Each of the lines and stages of the desalination system: in the simplified structure presented in Figure 2 , they would be denoted RO1A, RO1B, RO2A and $\mathrm{RO} 2 \mathrm{~B}$.

The control variables are then the connection of the SWP and the different sections of the Reverse Osmosis (See Figure 2).

\section{B. Control Objectives}

The main objectives can be written in a prioritized way as follows:

1. Keep all the buffer tanks over a minimum level, so that the next section can properly operate.

2. Once a unit of consumption is connected it should be maintained operating at its nominal value as long as there is enough energy.

C. Control Algorithm

The control strategy is based on two consecutive steps:

1. At each sampling time create a prioritized list of units of the water plant based on the current state of the plant (i.e., 
the tank levels and the units that are currently operating) and the expected water demand. This list of prioritized units is denoted $\left\{U_{i}\right\}_{i=1}^{N}$; a list of predicted energy demands is associated, denoted $\left\{E_{i}\right\}_{i=1}^{N}$. These lists are generated based on the knowledge of the process, in order to fulfill the requirements given in section III.B; for example, the following algorithm is used for the example in Figure 3 to generate $\left\{U_{i}\right\}_{i=1}^{N}$ :

1) Initialize $\left\{U_{i}\right\}=\{S W P, R O 1 A, R 01 \mathrm{~B}, R 02 A, R O 2 B\}$

2) At each sample time:

IF the level of SWT is LOW THEN

increase the priority of SWP

decrease the priority of RO1A and RO1B

IF the level of BT1 is LOW THEN

increase the priority of RO1A and RO1B

decrease the priority of RO2A and $\mathrm{RO} 2 \mathrm{~B}$

IF the level of BT2 is LOW THEN

increase the priority of $\mathrm{RO} 2 \mathrm{~A}$ and $\mathrm{RO} 2 \mathrm{~B}$

IF the level of SWT is HIGH THEN decrease the priority of SWP

increase the priority of RO1A and RO1B

IF the level of BT1 is HIGH THEN

decrease the priority of RO1A and RO1B

increase the priority of $\mathrm{RO} 2 \mathrm{~A}$ and $\mathrm{RO} 2 \mathrm{~B}$

IF the level of BT2 is HIGH THEN decrease the priority of RO2A and RO2B

2. Distribute the available energy among the units, following the prioritized list $\left\{U_{i}\right\}_{i=1}^{N},:$ : when possible energy is assigned to those units with higher priority. That is, a list of units that would be operating during the next sample, denoted $\left\{O_{j}\right\}_{j=1}^{m}$ is generated, together with the corresponding list of predicted energy demands $\left\{E O_{j}\right\}_{j=1}^{m}$; the elements disconnected would be $\left\{D_{j}\right\}_{j=1}^{N-m}$ with the corresponding unsatisfied energy demands $\left\{E D_{j}\right\}_{j=1}^{N-m}$. The energy consumed by the connected units fulfill

$$
\sum_{j=1}^{m} E O_{j} \leq E
$$

while all the units in the set of disconnected units fulfills

$$
E-\sum_{j=1}^{m} E O_{j} \leq E D_{k} \quad \forall k
$$

These lists can be generated by examining the list of predicted energy demands $\left\{E_{i}\right\}_{i=1}^{N}$ generated in parallel with $\left\{U_{i}\right\}_{i=1}^{N}$ as given by the following Algorithm:

At each sample time:

1) Initialize $\{E O\}=\{\} ;\{E D\}=\{\} ; m=0$;
2) FOR $i=1: N$

$$
\begin{gathered}
\text { IF } E_{i} \leq E-\sum_{j=1}^{m} E O_{j} \text { THEN } \\
m=m+1 \\
O_{m}=U_{i} \\
E O_{m}=E_{i}
\end{gathered}
$$

\section{OTHERWISE}

$$
\begin{aligned}
& D_{i-m}=U_{i} \\
& E D_{i-m}=E_{i}
\end{aligned}
$$




\section{CASE STUDY}

As a practical case study, the proposed control strategy was applied to a desalination plant for an industrial process, which was designed to operate producing up to $68 \mathrm{~m}^{3} / \mathrm{h}$ of demineralized water and up to $20 \mathrm{~m}^{3} / \mathrm{h}$ of drinkable and service water, consuming renewable electricity with variable production. A schematic diagram is presented in Figure 4. The characteristics of each of its units of consumption are as follows:

- A $51 \mathrm{~kW}$ seawater pump that provides a nominal flow rate of $256 \mathrm{~m}^{3} / \mathrm{h}$.

- The first stage or the Reverse Osmosis plant RO1 consists of two similar lines, each designed to produce $57 \mathrm{~m}^{3} / \mathrm{h}$ of water when connected (with a recovery ratio of around $45 \%$ ), consuming $155 \mathrm{~kW}$ per line (corresponding to approximately $2.7 \mathrm{kWh} / \mathrm{m}^{3}$ ) when they are operating.

- The second stage RO2 also consists of two similar lines, that, when connected, each line produces $34 \mathrm{~m}^{3} / \mathrm{h}$ of demineralized water (with a recovery ratio of around $75 \%$ ), consuming around $38 \mathrm{~kW}$ per line (approximately 1 $\mathrm{kWh} / \mathrm{m}^{3}$ of produced demineralized water).

To validate the proposed control system, meteorological data at the target location was used, and production models for power and water previously derived $[7,13,14]$ were used. Some preliminary results for 20 days of operation are shown in Figures 5 to 11. The evaluation over 20 days confirms the correct operation of the control system for the parameters considered in the previous sections. Figure 5 shows the power provided for each renewable energy source. WEC energy is more constant, though the value is smaller. The value of VAWT energy is almost $250 \mathrm{MW}$ in certain peak periods. As can be seen in Figure 6, the value of the power consumed by the system is lower than the available power. Figure 7 shows the three level tanks. In all cases, the levels are between the minimum and maximum levels that were defined to maintain them within a safety range. Figure 8 depicts the operation of the SWP. As expected, the SWP is not switched on/off very frequently (the exact value can be seen in Table 1). Figures 9 and 10 show the operation of the first and second Reverse Osmosis stages, respectively. As in the previous figure, the performance of both stages of the Reverse Osmosis process can be considered correct. Finally, Figure 11 depicts the amount of DEMI water that is consumed in the electrolysis process.

Table 1 summarizes the total parameters and consumption for the summer results. This corresponds to a mean production of $32.39 \mathrm{~m}^{3} / \mathrm{h}$ of water for the electrolysis, consuming a mean power of $219.79 \mathrm{~kW}$.

\section{CONCLUSION}

This paper has discussed the problem of operating desalination plants under variable power availability, which is a problem frequently encountered when local renewable energy sources are used in off-grid configurations. Using Smart Grid ideas, an heuristic control strategy has been proposed based on giving at each sample time preference to the connection of those components of the desalination plant that require urgent action to avoid not fulfilling the water demand; the buffer tanks makes possible to dampen

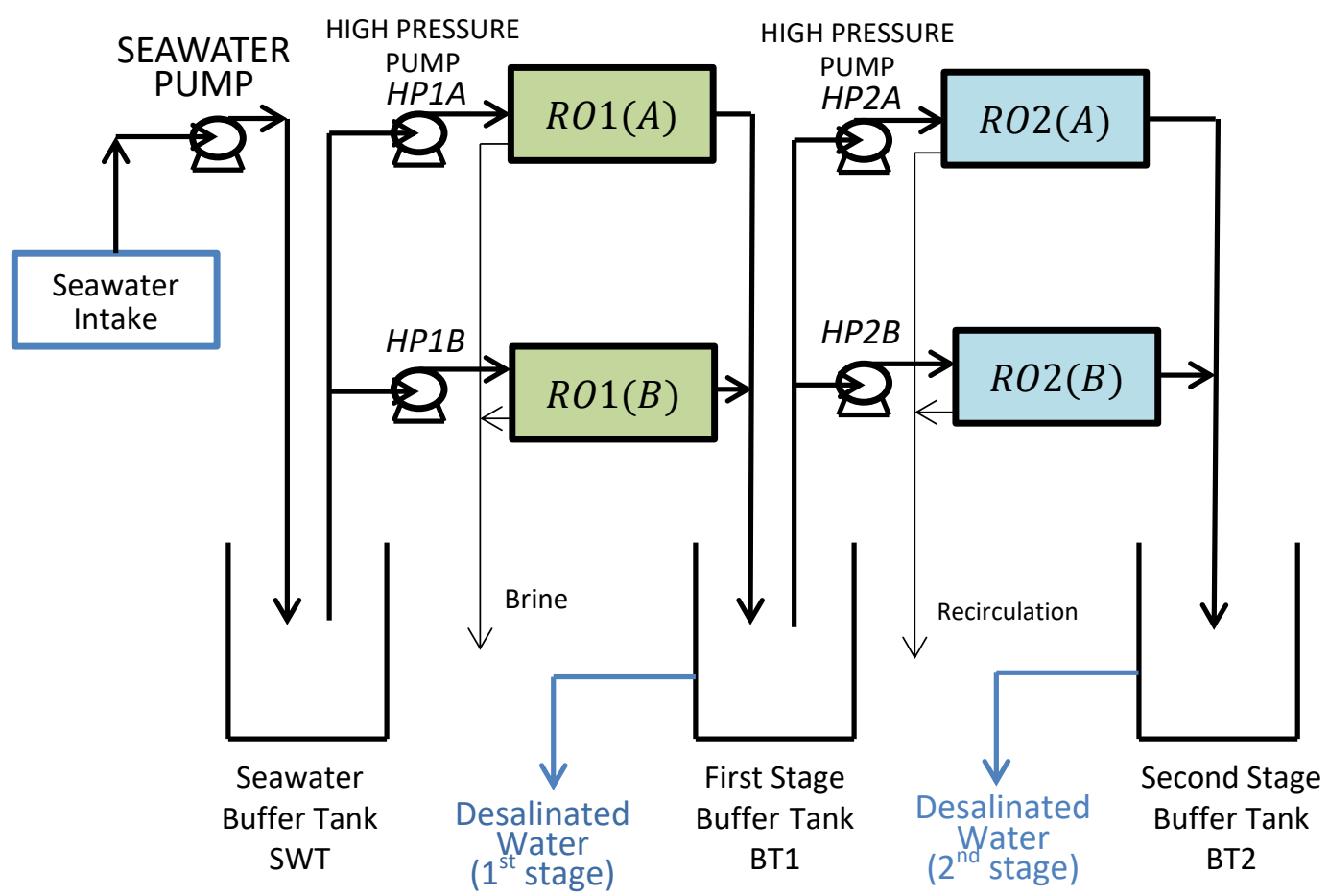

Figure 3: Structure of the desalination plants under study 
variations in production as long as they have enough water stored, so a central aspect of the control system is the use of the information of the measured tanks levels. The proposed controller was evaluated for a specific reverse osmosis plant that produces of demineralized water, powered by renewable energies. Some simulation results are provided to show the correct operation of the plant with the developed controller. It must be pointed out that the proposed approach is based on lines that operate at a fixed working point. However, recent technical advances in the integration of frequency variators in high pressure pumps would make for some applications more adequate to operate the lines at variable working points: the adaptation of the proposed control strategy to this alternative installations would be the subject of further work.

Moreover it is planned to extend the proposal to include information on predicted energy availability and water demand.

\section{ACKNOWLEDGMENT}

This work was funded by Ministerio de Ciencia e Innovación (Spain) under grant DPI2014-54530-R. The authors would like to thank the partners of the H2Ocean project for their contribution $_{\S 8 \mathrm{KW}}$

\section{REFERENCES}

[1] Garcia-Rodriguez, L. (2002). "Seawater desalination driven by renewable energies: a review". Desalination, 143:103-113.

[2] Mathioulakis, E., Belessiotis, V., and Delyannis, E. (2007). "Desalination by using alternative energy: Review and state-of-theart", Desalination, 203:346-365.
[3] Wong, M. C. Y., Martinez, K., Ramon, G. Z., and Hoek, E. M. V. (2012). "Impacts of operating conditions and solution chemistry on osmotic membrane structure and performance". Desalination, 287:340-349

[4] Fritzmann, C., Lowenberg, J., Wintgens, T., and Melin, T. (2007). "State-of-the-art of reverse osmosis desalination". Desalination, 216:1-76

[5] Penate, B. and Garcia-Rodriguez, L. (2012). "Current trends and future prospects in the design of seawater reverse osmosis desalination technology". Desalination, 284:1-8.

[6] Seibert, U., Vogt, G., Brenning, C., Gebhard, R., Holz, F "Autonomous, desalination system concepts for seawater and brackish water in rural areas with renewable energies". Desalination, vol. 168, pp. 29-37, 2004.

[7] Tadeo, F., Palacin, L. G., Salazar, J., and de Prada, C. (2011). "Desalination in remote areas: A prediction-based approach", in Proc. IDA World Congress, Perth, Australia.

[8] Peas Lopes, J. A., Moreira, C. L., \& Madureira, A. G. (2006) "Defining control strategies for microgrids islanded operation". IEEE Transactions on Power Systems, 21(2), 916-924.

[9] Vandoorn, T. L., Renders, B., Degroote, L., Meersman, B., \& Vandevelde, L. (2011). "Active load control in islanded microgrids based on the grid voltage". IEEE Transactions on Smart Grid, 2(1), 139-151.

[10] Robertson, M. W., Watters, J. C., Desphande, P. B., Assef, J. Z., and Alatiqi, I. M. (1996). "Model based control for reverse osmosis desalination processes". Desalination, 104:59-68

[11] Gambier, A. and Badreddin, E. (2003). "Application of hybrid modeling and control techniques to desalination plants". Desalination, 152:175-184.

[12] Palacin, L., Tadeo, F., de Prada, C., Elfil, H., Salazar J. "Operation of desalination plants using hybrid control". Desalination and Water Treatment. Vol. 25, pp. 119-126, 2011.

[13] Serna, A., Tadeo, F., "Offshore desalination using wave energy", Advances in Mechanical Engineering vol. 2013, Article ID 539857, 8 pages, 2013.

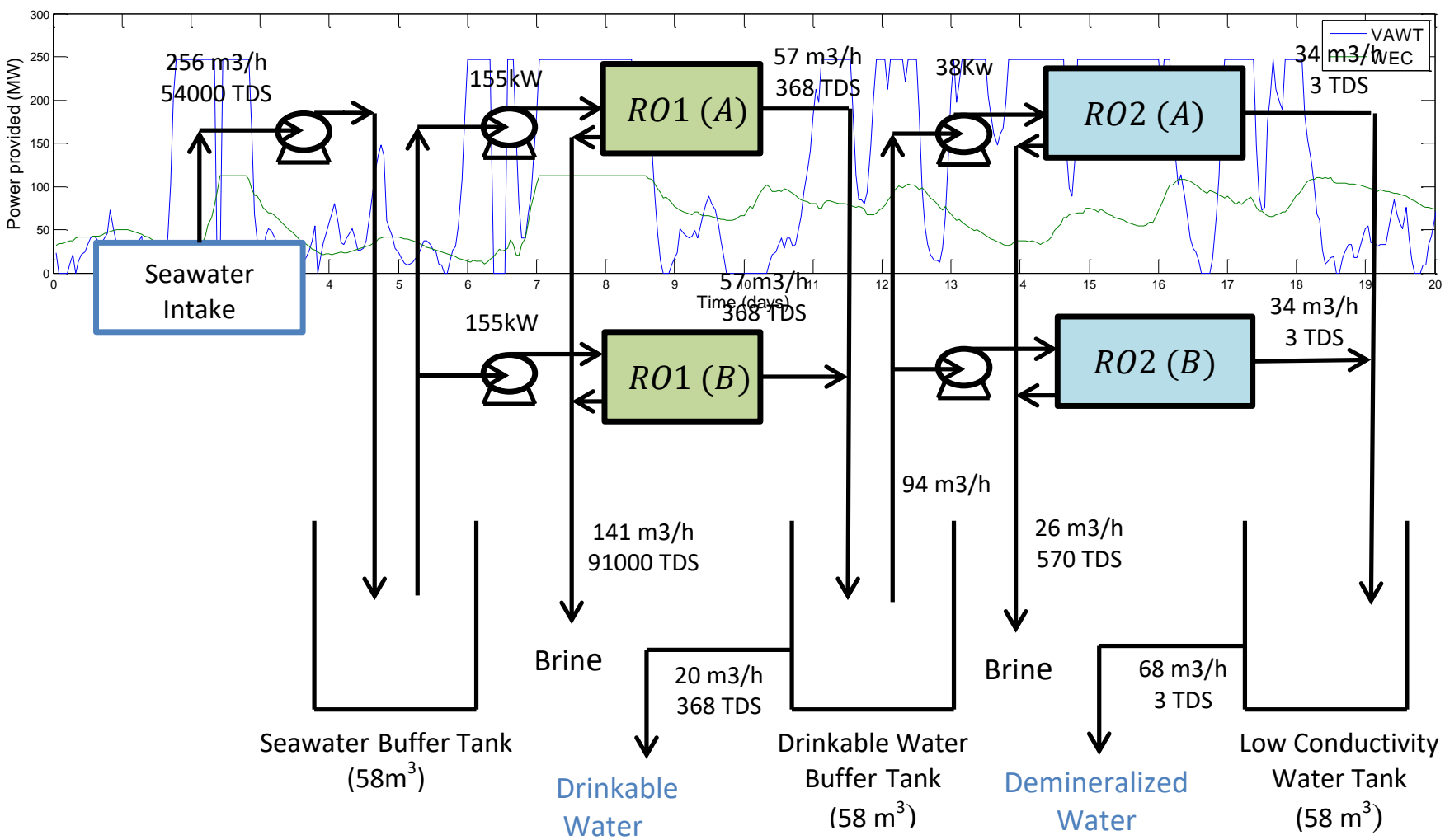

Figure 4: Case Study 
Figure 5: Power provided (20 days of winter) by each renewable energy source

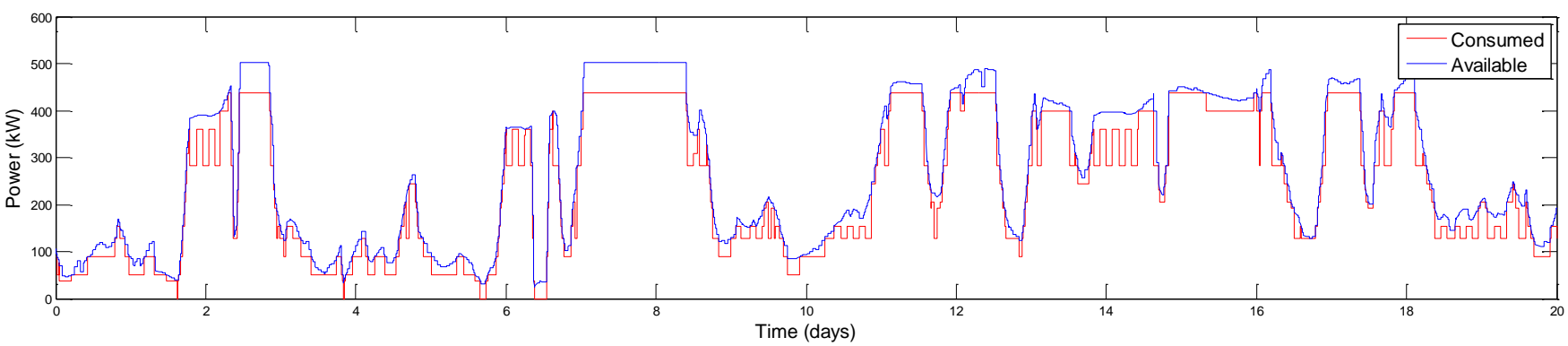

Figure 6: Power available and consumed by the desalination unit (winter)

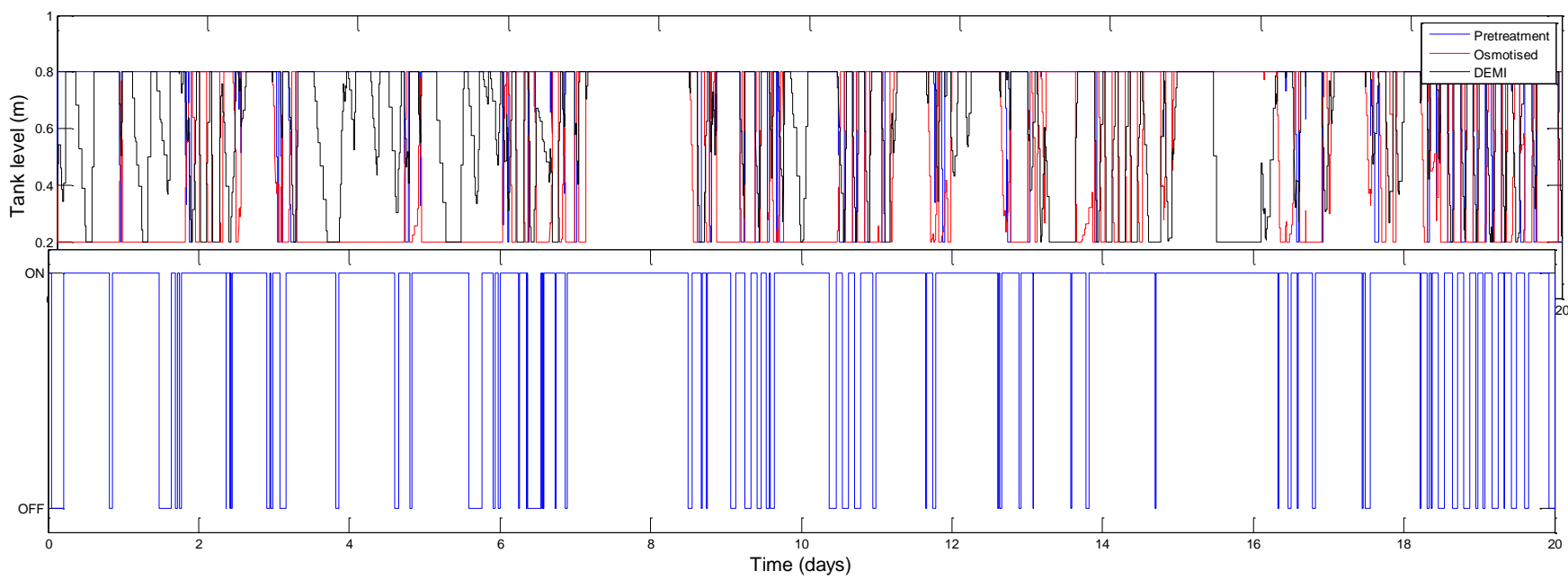

Figure 8: Operation of the seawater pump

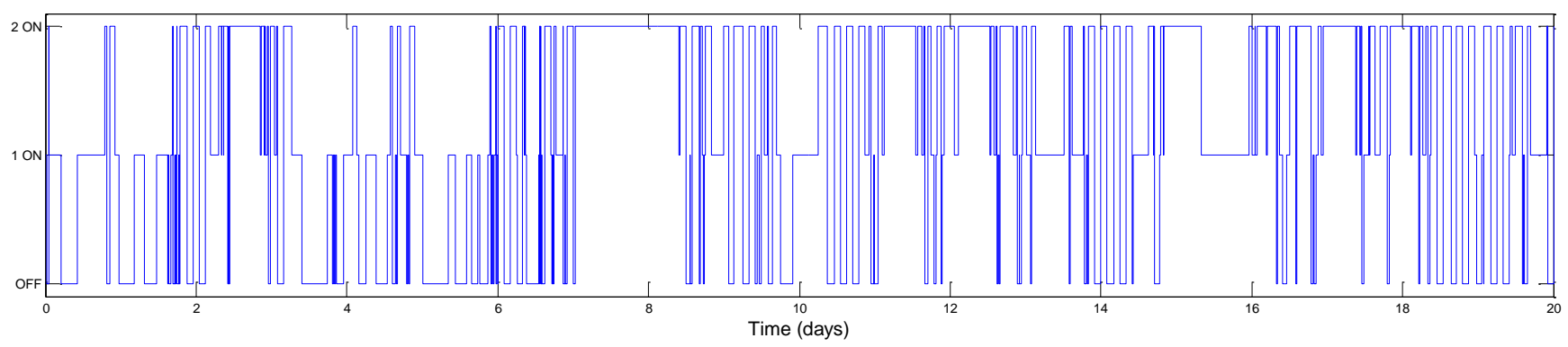

Figure 9: Operation of the first stage of the desalination unit

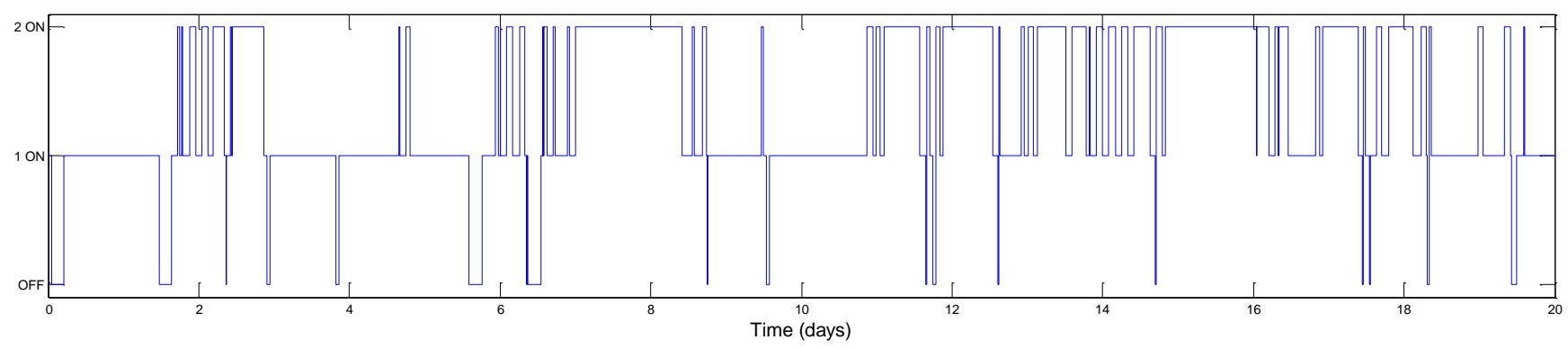


Figure 10: Operation of the second stage of the desalination unit

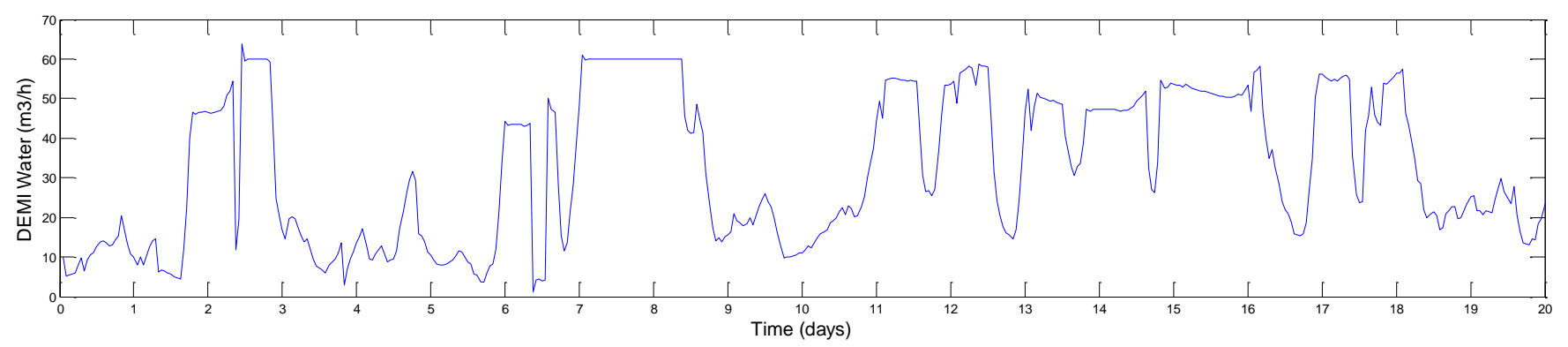

Figure 11: Water flow to electrolyzers

\begin{tabular}{ccccccc|}
$\begin{array}{c}\text { Mean Power } \\
\text { Available } \\
(\mathrm{kW})\end{array}$ & $\begin{array}{c}\text { Mean Power } \\
\text { Consumed } \\
(\mathrm{kW})\end{array}$ & $\begin{array}{c}\text { DEMI } \\
\text { Water } \\
\left(\mathrm{m}^{3} / \mathrm{h}\right)\end{array}$ & $\begin{array}{c}\text { Osmotised } \\
\text { Water } \\
\left(\mathrm{m}^{3} / \mathrm{h}\right)\end{array}$ & $\begin{array}{c}\text { Sea Water Pump } \\
\text { ON/OFF } \\
\text { (times/day) }\end{array}$ & $\begin{array}{c}1^{\text {st }} \text { Reverse } \\
\text { Osmosis Stage } \\
\text { ON/OFF } \\
\text { (times/day) }\end{array}$ & $\begin{array}{c}2^{\text {nd }} \text { Reverse } \\
\text { Osmosis Stage } \\
\text { ON/OFF } \\
\text { (times/day) }\end{array}$ \\
\hline 271.66 & 219.79 & 32.39 & 55.71 & 5.8 & 6.2 & 14.6 \\
\hline
\end{tabular}

Table 1: Parameters and consumptions 